\title{
BMJ open GPs' perspectives on the management of patients with multimorbidity: systematic review and synthesis of qualitative research
}

\author{
Carol Sinnott, ${ }^{1}$ Sheena Mc Hugh, ${ }^{2}$ John Browne, ${ }^{2}$ Colin Bradley ${ }^{1}$
}

To cite: Sinnott C, Mc Hugh S, Browne J, et al. GPs' perspectives on the management of patients with multimorbidity: systematic review and synthesis of qualitative research. BMJ Open 2013;3:e003610. doi:10.1136/bmjopen-2013003610

- Prepublication history and additional material for this paper is available online. To view these files please visit the journal online (http://dx.doi.org/10.1136/ bmjopen-2013-003610).

Received 17 July 2013 Accepted 2 August 2013

${ }^{1}$ Department of General Practice, University College Cork, Cork, Ireland ${ }^{2}$ Department of Epidemiology \& Public Health, University College Cork, Cork, Ireland

Correspondence to Dr Carol Sinnott; csinnott@ucc.ie

\section{ABSTRACT}

Objective: To synthesise the existing published literature on the perceptions of general practitioners (GPs) or their equivalent on the clinical management of multimorbidity and determine targets for future research that aims to improve clinical care in multimorbidity.

Design: Systematic review and metaethnographic synthesis of primary studies that used qualitative methods to explore GPs' experiences of clinical management of multimorbidity or multiple chronic diseases.

Data sources: EMBASE, MEDLINE, CINAHL, PsycInfo, Academic Search Complete, SocIndex, Social Science Full Text and digital theses/online libraries (database inception to September 2012) to identify literature using qualitative methods (focus groups or interviews).

Review methods: The 7-step metaethnographic approach described by Noblit and Hare, which involves cross-interpretation between studies while preserving the context of the primary data.

Results: of 1805 articles identified, 37 were reviewed in detail and 10 were included, using a total of 275 GPs in 7 different countries. Four areas of difficulty specific to the management of multimorbidity emerged from these papers: disorganisation and fragmentation of healthcare; the inadequacy of guidelines and evidence-based medicine; challenges in delivering patient-centred care; and barriers to shared decision-making. A 'line of argument' was drawn which described GPs' sense of isolation in decision-making for multimorbid patients.

Conclusions: This systematic review shows that the problem areas for GPs in the management of multimorbidity may be classified into four domains. There will be no 'one size fits all' intervention for multimorbidity but these domains may be useful targets to guide the development of interventions that will assist and improve the provision of care to multimorbid patients.

\section{INTRODUCTION}

Multimorbidity, the coexistence of two or more long-term conditions in one patient, is increasingly the norm in primary care

\section{ARTICLE SUMMARY}

Strengths and limitations of this study

- The metaethnographic approach used in this review gave a broader understanding of the challenges of multimorbidity than any single study, while still preserving the context of included studies.

- We focused on the general practitioners' perspective on multimorbidity - an understanding of the challenges experience by patients is also required to inform the development of effective interventions.

chronic disease management. ${ }^{1} 2$ The management of patients with multiple morbidities presents unique challenges to healthcare providers, and there is evidence that patients with multimorbidity receive a lower quality of care than those with single diseases. ${ }^{3}{ }^{4}$ Healthcare utilisation, hospitalisation rates and total healthcare costs are higher among multimorbid patients, even in systems where access to secondary care is restricted to referral by a primary care physician. $^{5-7}$

The epidemiology of multimorbidity is thus well described, and there is currently a need for interventions to improve healthcare in this patient group. ${ }^{8} 9$ A necessary step in the development of interventions is to understand why problems arise and what processes in the delivery of care are amenable to change. Interviews with stakeholders, such as healthcare providers, can be important sources of this information. ${ }^{10}$ To date, qualitative studies from a range of countries have elicited general practitioners' (GPs') views on challenges in the clinical management of multimorbidity, with diverse and sometimes conflicting findings. A synthesis of these studies has the potential to achieve a greater 
conceptual understanding of the challenges associated with multimorbidity than a single empirical study.

Metaethnography, one of the most commonly used methods for synthesising qualitative research studies, employs a process of comparison and crossinterpretation between studies while preserving the context of primary data. ${ }^{11}$ Similar to traditional systematic reviews, this process can generate new insights, highlight gaps in our knowledge and identify areas of data saturation where no further primary research is required. ${ }^{12}$

An awareness of the overall picture of the challenges faced by GPs in multimorbidity is needed to direct research efforts and intervention design in this field. To achieve this, we synthesised and analysed the existing literature on the views of GPs on the management of multimorbid patients and determined targets for future research to improve multimorbidity care.

\section{METHODS}

The seven-step model of metaethnography described by Noblit and Hare ${ }^{13}$ was used.

The first step involved a clear statement of the specific research question and the contribution it will make to the field.

In step 2, a search strategy was devised to retrieve articles related to this aim. We focused our search to locate primary studies that used qualitative methods to explore the clinical management of multimorbidity or multiple chronic diseases by GPs or their equivalent. We searched seven databases using database-specific search terms and validated methods for retrieving qualitative studies: EMBASE (Elsevier), MEDLINE (Ovid), CINAHL, PsycInfo, Academic Search Complete, SocIndex, Social Science Full Text (all Ebsco; see online supplementary appendix 1). ${ }^{14-17}$ We supplemented this by searching databases of grey literature and reference lists. The search was not limited by language or dates of publication. The titles and abstracts of retrieved citations were read by one reviewer (CS). Full articles were ordered for all potentially relevant abstracts. ${ }^{18}$ These articles were reviewed by two researchers (CS and CB) and were included if they fulfilled our inclusion criteria. Studies that examined the management of multimorbidity as part of a wider research question were included. We assessed the quality of included studies using the Critical Appraisal Skills Programme (CASP) for qualitative research. ${ }^{19}$ Assessment of study quality was not a criteria to exclude studies that otherwise met the inclusion criteria, but gave useful insights into the methods used for data collection and analysis.

Step 3 of the metaethnographic synthesis involved reading the studies. Initially two reviewers (CS and $\mathrm{CB}$ ) read and re-read the included studies, and independently listed the main findings from each one. Study findings were defined as all data in the results and discussion sections of the included articles-including both the first-order interpretations (views of the participants) and second-order interpretations (views of authors). In studies in which GPs were interviewed with another healthcare professional, the analysis was restricted to the views of the GP where possible.

In step 4, we determined how the studies were related to each other by comparing individual study findings. Four key concepts were chosen which reflected the main findings of all included studies. We also abstracted data on standard fields, such as study aims, design, methods, setting and participants (see online supplementary appendix 3). ${ }^{20}$ Data were entered into QSR International's NVivo V.9 software to assist our qualitative analysis and synthesis. ${ }^{21}$

In step 5, studies were translated into each other by examining the contribution of each study to a key concept. Within the key concepts, similarities and differences in study findings and contexts were noted, and deviant cases were sought. To address the potential for clinical bias a third reviewer with a non-medical background (SMH) independently read all included articles and cross-checked the derivation and development of the key concepts.

In step 6, we synthesised the translations in each key concept to develop third-order interpretations, or higher levels of abstraction of the data for each key concept. We linked the third-order interpretations using a 'line of argument', which represented the overarching perspective of GPs towards multimorbidity.

The final step involved expressing the results of the synthesis, for which we used tables, figures and text. The 'Enhancing transparency in reporting the synthesis of qualitative research' (ENTREQ) statement was used to inform the reporting of our results (see online supplementary appendix 4).$^{22}$ Additionally, a summary of our findings were provided to the first authors of all included articles, to validate our findings as representative of the original sources.

\section{Results}

The electronic database search returned 2005 citations, leaving 1805 citations after removal of duplicates (figure 1 ). A further 1768 citations were excluded by reading the title or abstract: 48 did not concern primary care, 891 were not qualitative studies, 769 did not concern multimorbidity and 60 did not concern the GP's perspective. Full-text articles were retrieved for 37 citations. Eleven of these were excluded because they did not use qualitative methods. A further 16 articles were excluded because, although they concerned patients with multiple chronic diseases, their exploration was focused on the management of an index disease. One possible relevant citation was in abstract form only (the study authors were contacted and the full account of this data has not been published yet; see online supplementary appendix 2). One additional study was retrieved from reference searching of the nine remaining studies. Ten studies were included in the final synthesis (table 1).

The included studies were conducted in seven countries: Belgium, England, Germany, Ireland, Scotland, 
Figure 1 Flow diagram of search.

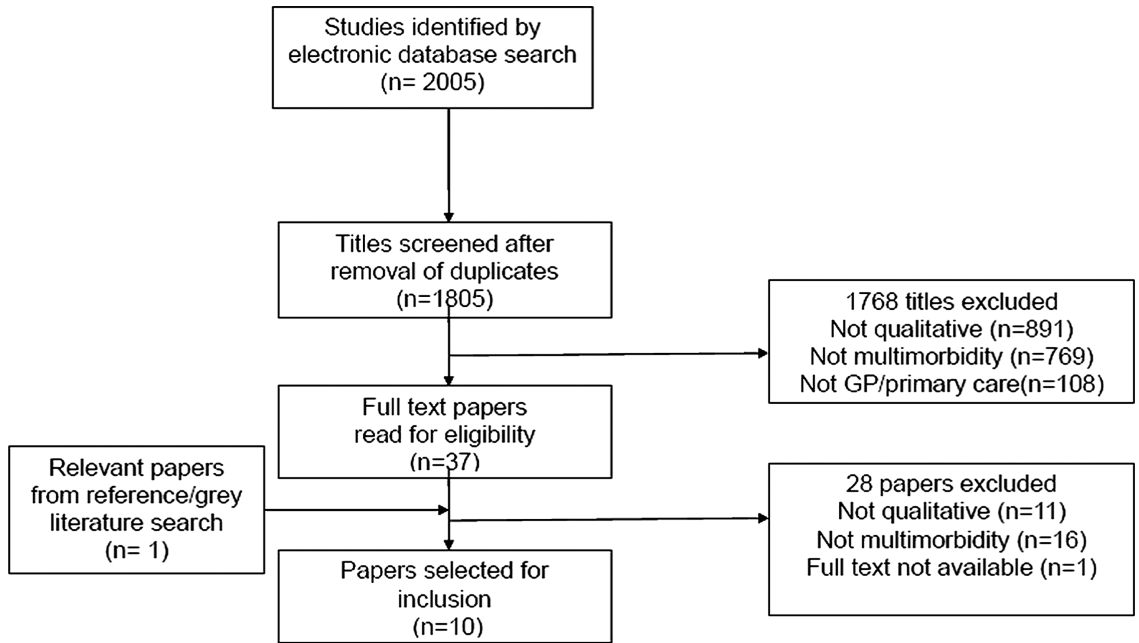

The Netherlands and the USA. A total of 275 GPs were involved; five studies used focus groups and five used interviews with individual GPs. One of the included articles was published in German. The authors were contacted for an English translation and as none was available the article was translated by a native German speaker in collaboration with CS. The overall quality of the 10 included studies was high, with all articles meeting the majority of CASP criteria. The most common weaknesses were related to data saturation (not reported in six studies) ${ }^{23-28}$ and reflexivity (not discussed in five studies). ${ }^{25-27} 2930$ GPs with academic/ research affiliations were over-represented as research subjects in five studies, representing a potential source of bias. ${ }^{23} 26$ 29-31

Six studies primarily focused on multimorbidity. In these, multimorbidity was defined for study participants as two or more chronic diseases 24262932 or introduced to participants using a multimorbid case vignette ${ }^{30}$ or an editorial on multimorbidity. ${ }^{23}$ Four studies retrieved by our search did not focus primarily on multimorbidity but were included as multimorbidity emerged as an important issue for study participants; two studies addressed polypharmacy ${ }^{28} 31$ and two explored the role of guidelines in primary care. ${ }^{25} 27$

\section{Translation of included studies}

GPs in all studies reported challenges in multimorbidity, which they faced with 'moderate optimism to something close to despair'. ${ }^{30}$ Even in the context of deprivation, some participants reported feeling like a 'wrung out rag' after complex multimorbidity consultations while others felt 'energised' by the 'privilege and rewards' that could be obtained from working in such a complex environment. ${ }^{24}$ Four key concepts that reflected the principal findings of all included studies were determined. These are reported below and shown in table 2. Within each key concept, subthemes arose and are highlighted in bold.

\section{Disorganisation and fragmentation of healthcare}

The included studies covered a range of different health systems, all of which lacked specific systems for treating patients with multimorbidity. In most studies this lack of organisation hampered care by causing logistical difficulties and excess consultation demands on the patient and their GP. Only one study mentioned that these problems were not serious enough to warrant a change in service organisation. $^{29}$

The prevailing structure of primary healthcare reduced GPs' ability to respond to the needs of patients with multimorbidity. Insufficient consultation time led to amended or suboptimal approaches in many cases. $^{2324} 29$ It was suggested that weighting consultation lengths to the complexity of multimorbidity would facilitate more effective management. ${ }^{23} 29$

Fragmented care resulted from 'the involvement of several medical specialists, who each emphasize the importance of 'their' guideline' ${ }^{30}$ and 'poor communication from specialists and hospitals to the family physician' ${ }^{31}$ which meant that 'coordination and overview on medication were hard to maintain'. ${ }^{2}$ In some studies, GPs had a broad sense of responsibility towards overseeing and screening patients' medications ${ }^{28} 31$ 32; others were unsure about their role in screening prescriptions and felt that a clear line of responsibility was required. ${ }^{23}$ It was suggested that specialists did not 'consider the wider harms and benefits of organ-specific intervention', thereby adding to the problems of multimorbidity, in contrast to GPs who had a 'holistic' view of the patient; 'The cardiologists, you know, don't mind if they bleed to death'. ${ }^{26}$

Despite these reservations, the input of specialists was desired. A 'balance of equals' was called for, that would allow GPs and specialists to discuss complex patients and improve the awareness of complexity in multimorbidity among specialists. ${ }^{23} 31$ This would help all doctors involved 'to speak with one voice. Different stories provoke distrust'. 30 


\begin{tabular}{|c|c|c|c|c|c|c|}
\hline $\begin{array}{l}\text { First } \\
\text { author }\end{array}$ & Objective & Data collection & Participants (n) & $\begin{array}{l}\text { Qualitative } \\
\text { methodology/ } \\
\text { analysis }\end{array}$ & Country & $\begin{array}{l}\text { Year of } \\
\text { publication }\end{array}$ \\
\hline $\begin{array}{l}\text { Smith } \\
\text { et }\left.a\right|^{R^{3}}\end{array}$ & $\begin{array}{l}\text { To explore the views and attitudes } \\
\text { of GPs and pharmacists managing } \\
\text { patients with multimorbidity in } \\
\text { primary care }\end{array}$ & $\begin{array}{l}\text { Focus group with topic guide; } \\
\text { participants were given a } \\
\text { published editorial on } \\
\text { multimorbidity before hand }\end{array}$ & $\begin{array}{l}\text { GPs }{ }^{13} \text { and pharmacists. } \\
\text { GPs were tutors to } \\
\text { undergraduate medical students, } \\
\text { worked in a mix of rural/urban, } \\
\text { deprived/affluent practice and } \\
\text { varied by gender and years of } \\
\text { experience }\end{array}$ & Framework & Ireland & 2010 \\
\hline $\begin{array}{l}\text { O'Brien } \\
\text { et } a \text { f }^{4}\end{array}$ & $\begin{array}{l}\text { To understand GPs and practice } \\
\text { nurses' experiences of managing } \\
\text { multimorbidity in deprived areas } \\
\text { and elicit views on what might help }\end{array}$ & $\begin{array}{l}\text { Individual semistructured } \\
\text { interview facilitated by researched } \\
\text { topic guide }\end{array}$ & $\begin{array}{l}\mathrm{GPs}^{15} \text { and nurses, working in } \\
\text { areas of high deprivation in } \\
\text { Scotland }\end{array}$ & $\begin{array}{l}\text { Constant } \\
\text { comparison }\end{array}$ & Scotland & 2011 \\
\hline $\begin{array}{l}\text { Steinman } \\
\text { et } a^{25}\end{array}$ & $\begin{array}{l}\text { To investigate clinician attitudes } \\
\text { about the usefulness of heart } \\
\text { failure guidelines in patients of } \\
\text { various ages/morbidity }\end{array}$ & $\begin{array}{l}\text { Telephone-based interview using } \\
\text { Likert scales followed by } \\
\text { open-ended questions }\end{array}$ & $\begin{array}{l}\text { Primary Care Practitioners (48/ } \\
58) \text { and Internists (10/58) } \\
\text { responsible for suboptimally } \\
\text { managed patients with heart } \\
\text { failure }\end{array}$ & Content analysis & USA & 2012 \\
\hline Fried et $a^{26}$ & $\begin{array}{l}\text { To explore clinicians' perspectives } \\
\text { of and experiences with } \\
\text { therapeutic decision-making for } \\
\text { older persons with multiple medical } \\
\text { conditions }\end{array}$ & $\begin{array}{l}\text { Focus groups with broad } \\
\text { discussion initially then focused } \\
\text { questions on polypharmacy, side } \\
\text { effects and evidence-based } \\
\text { medicine in multimorbidity }\end{array}$ & $\begin{array}{l}\mathrm{GPs}^{36} \text { purposively sampled to } \\
\text { vary on academic, community } \\
\text { and Veteran Affair settings }\end{array}$ & Content analysis & USA & 2011 \\
\hline $\begin{array}{l}\text { Solomon } \\
\text { et } a^{27}\end{array}$ & $\begin{array}{l}\text { To explore the relationship } \\
\text { between prescribing guidelines and } \\
\text { patient partnership by exploring the } \\
\text { attitudes of patients, GPs and PCT } \\
\text { prescribing advisors }\end{array}$ & Semistructured interviews & $\begin{array}{l}\mathrm{GPs}^{8} \text { sampled using maximum } \\
\text { variation by location, gender, } \\
\text { single versus group practice }\end{array}$ & Framework & England & 2012 \\
\hline $\begin{array}{l}\text { Anthierens } \\
\text { et } a R^{28}\end{array}$ & $\begin{array}{l}\text { To describe GPs' views and beliefs } \\
\text { on polypharmacy }\end{array}$ & Semistructured interviews & $\begin{array}{l}65 \text { GPs working in mixed rich/ } \\
\text { poor urban environment }\end{array}$ & Content analysis & Belgium & 2010 \\
\hline $\begin{array}{l}\text { Bower } \\
\text { et } a^{29}\end{array}$ & $\begin{array}{l}\text { To explore GP and nurse } \\
\text { perceptions of multimorbidity and } \\
\text { the influence on service } \\
\text { organisation and clinical } \\
\text { decision-making }\end{array}$ & $\begin{array}{l}\text { Individual semistructured } \\
\text { interview using topic guide with } \\
\text { questions and case vignettes }\end{array}$ & $\begin{array}{l}\text { GPs }{ }^{15} \text { and nurses, working in a } \\
\text { pay for performance system } \\
\text { (NHS). Purposively sampled } \\
\text { from research network, to vary } \\
\text { on list size and deprivation }\end{array}$ & Framework & England & 2011 \\
\hline $\begin{array}{l}\text { Schuling } \\
\text { et }\left.a\right|^{\beta 0}\end{array}$ & $\begin{array}{l}\text { To explore how experienced GPs } \\
\text { feel about deprescribing } \\
\text { medication in older patients with } \\
\text { multimorbidity and to what extent } \\
\text { they involve patients in these } \\
\text { decisions }\end{array}$ & Focus groups & $\begin{array}{l}\mathrm{GPs}^{29} \text { split into three groups. All } \\
\text { were GP trainers of at least } \\
5 \text { years experience 'used to } \\
\text { reflecting on their practice' }\end{array}$ & Thematic & $\begin{array}{l}\text { The } \\
\text { Netherlands }\end{array}$ & 2012 \\
\hline Marx et $a \beta^{\beta 1}$ & & Focus groups & & & Germany & 2009 \\
\hline
\end{tabular}




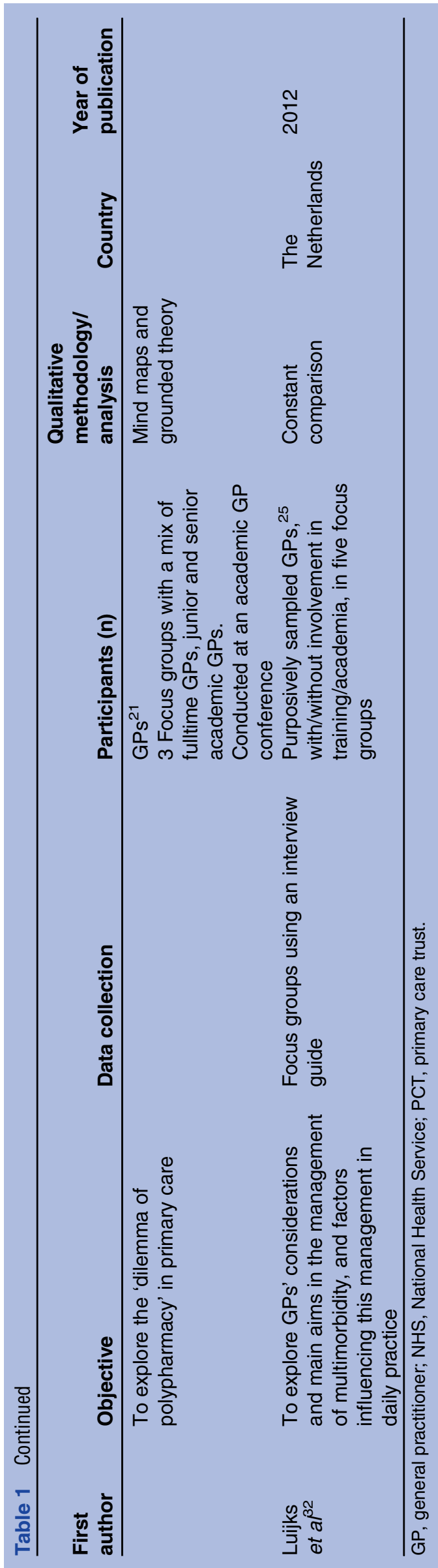

Inadequacy of guidelines and evidence-based medicine

There was concern among GPs about clinical guidelines, which are 'generally written for sole conditions' and do not account for 'the unique circumstances of each patient'. ${ }^{25}$ Most GPs felt that guidelines were less useful in multimorbidity and that they actually added to the complexity in some cases: 'no one can tell you the added benefit of an additional agent for blood pressure if you are already on ten'. ${ }^{26}{ }^{30}$ However, others felt that using guidelines in multimorbidity ensured that patients received the best quality care: "why should their asthma be treated any differently just because they've got asthma and heart disease and you know osteoporosis or whatever'. ${ }^{29}$

GPs doubted whether the evidence underpinning guidelines could be extrapolated to patients with multimorbidity: 'the guidelines are going to be set for optimum situations, and someone with multiple comorbidities [is] not going to be optimum'. ${ }^{25-27} 31$ They also questioned the relevance of disease-specific outcomes and guideline recommendations on the use of primary prevention (ie, antihypertensive or lipid-lowering agents) in multimorbidity, preferring to orient management to symptoms or quality of life. ${ }^{23} 25$

GPs used modified approaches to guidelines, involving, for example, the estimation of risk associated with particular diseases/treatments. ${ }^{26}{ }^{30}$ However, some felt that this modification was in conflict with 'best practice' and felt guilt at not implementing guidelines fully. ${ }^{24} 30$ Initiatives that linked physician reimbursement with adherence to guidelines were seen as a threat to GPs' ability to deliver patient-centred care. ${ }^{24} 26$

\section{Challenges in delivering patient-centred care}

In response to the various demands of multimorbidity, GPs recognised the importance of delivering patientcentred care, which incorporated two principal concepts: an individualised management and a generalist approach. ${ }^{23-26}$ 28-32 Delivering patient-centred care was seen as an aid for some but a challenge for others. For instance, some GPs felt that taking a broader view of the patient, incorporating non-medical or psychosocial issues, increased the level of complexity in their management. ${ }^{24}$ However for others, adopting a patient-centred approach was seen as a way of resolving the conflicts and uncertainty that can occur, particularly with coimplementation of multiple sets of guidelines. ${ }^{24} 32$

In most studies, the longitudinal nature of the patientGP relationship was seen as a 'major facilitator' and 'elementary component' of patient-centred care in multimorbidity. ${ }^{23}{ }^{24}{ }^{28-32}$ Within the specific context of deprivation, longitudinal care was "potentially transformative' by providing 'time to build relationships with patients' but it was also a source of problems, by creating dependence and increased demands by patients for consultations. ${ }^{24}$ The impact of treatment burden was an important consideration given the greater costs and risk of adverse drug events associated with the use of 
Table 2 Translations between studies with third order interpretation and line of argument formation

\begin{tabular}{|c|c|c|c|c|}
\hline First author & $\begin{array}{l}\text { Disorganisation and } \\
\text { fragmentation of } \\
\text { healthcare }\end{array}$ & $\begin{array}{l}\text { The inadequacy of } \\
\text { guidelines and } \\
\text { evidence-based } \\
\text { medicine }\end{array}$ & $\begin{array}{l}\text { Challenges in } \\
\text { patient-centred care }\end{array}$ & $\begin{array}{l}\text { Challenges in shared } \\
\text { decision-making }\end{array}$ \\
\hline Smith et $a^{R^{3}}$ & $\begin{array}{l}\text { lines of communication } \\
\text { need time and nobody } \\
\text { appears to have time } \\
\text { collusion of anonymity, } \\
\text { which is, you know, this } \\
\text { is not my patient, not my } \\
\text { patient }\end{array}$ & $\begin{array}{l}\text { the paradox faced by } \\
\text { conscientious GPs in } \\
\text { attempting to balance } \\
\text { the potentially competing } \\
\text { demands of health } \\
\text { promotion, } \\
\text { evidence-based } \\
\text { medicine and the use of } \\
\text { multiple medications }\end{array}$ & $\begin{array}{l}\text { a focus on function and } \\
\text { quality of life was } \\
\text { preferable to considering } \\
\text { specific-disease outcome } \\
\text { measures }\end{array}$ & $\begin{array}{l}\text {..decision making very } \\
\text { difficult to achieve. } \\
\text { decisions were linked to } \\
\text { the theme of avoidance } \\
\text { of complex issues } \\
\text { which...can appear to } \\
\text { become increasingly } \\
\text { problematic and } \\
\text { unsolvable }\end{array}$ \\
\hline O'Brien et $a R^{4}$ & $\begin{array}{l}\text { adaptation of existing } \\
\text { practice systems, } \\
\text { particularly appointment } \\
\text { length, relationship } \\
\text { continuity and referral } \\
\text { systems for resources } \\
\text { outside primary care, } \\
\text { may improve services } \\
\text { from the perspectives of } \\
\text { professionals }\end{array}$ & $\begin{array}{l}\text { need .. to demonstrate } \\
\text { that we are interested in } \\
\text { (patients) as a person, } \\
\text { not someone who has } \\
\text { heart failure }\end{array}$ & $\begin{array}{l}\text { wanted to develop } \\
\text { relationships with patients } \\
\text { because she thought that } \\
\text { greater understanding of } \\
\text { their circumstances would } \\
\text { help her get to the root of } \\
\text { (medical) problems }\end{array}$ & $\begin{array}{l}\text { there was a need to } \\
\text { address 'a bit of the } \\
\text { patient's agenda and } \\
\text { our agenda' within } \\
\text { consultations }\end{array}$ \\
\hline $\begin{array}{l}\text { Steinman } \\
\text { et } a^{R^{5}}\end{array}$ & - & $\begin{array}{l}\text {...those with multiple } \\
\text { comorbid conditions } \\
\text { were more likely to } \\
\text { experience harm from } \\
\text { aggressive } \\
\text { guideline-based } \\
\text { treatments } \\
\text { guidelines represent a } \\
\text { criterion standard of } \\
\text { evidence-based care.... } \\
\text { regardless of patient age } \\
\text { or comorbid burden }\end{array}$ & $\begin{array}{l}\text { Each patient is a unique } \\
\text { situation and is not going } \\
\text { to be the same as another } \\
\text { patient.... We have to go } \\
\text { by the individual patient, } \\
\text { by the patient's comfort, } \\
\text { how is he feeling and how } \\
\text { is he doing }\end{array}$ & $\begin{array}{l}\text { a suggested approach } \\
\text { to decision making for } \\
\text { older adults that } \\
\text { provides guidance on } \\
\text { prioritising care, } \\
\text { accounting for comorbid } \\
\text { conditions and factoring } \\
\text { in the role of estimated } \\
\text { life expectancy }\end{array}$ \\
\hline Fried et $a{ }^{26}$ & $\begin{array}{l}\text { fragmentation of care for } \\
\text { patients who receive } \\
\text { care for their multiple } \\
\text { conditions from many } \\
\text { physicians. } \\
\text { the limitations imposed } \\
\text { by current } \\
\text { reimbursement systems, } \\
\text { which fail to } \\
\text { acknowledge the } \\
\text { complexities of caring } \\
\text { for older persons with } \\
\text { multiple conditions }\end{array}$ & $\begin{array}{l}\text { If they cannot manage ... } \\
\text { I am not going to } \\
\text { complicate it further by } \\
\text { adding something to get } \\
\text { to the goal range. } \\
\text { other clinicians believed } \\
\text { that guideline-directed } \\
\text { care would produce the } \\
\text { best outcomes }\end{array}$ & $\begin{array}{l}\text { Tailoring their approach ... } \\
\text { from a consideration of } \\
\text { such factors as patients' } \\
\text { cognition and availability of } \\
\text { social support }\end{array}$ & $\begin{array}{l}\text {...conflicts between } \\
\text { what they wanted to do } \\
\text { for the patient and what } \\
\text { the patient wanted } \\
\text {...patients' and families' } \\
\text { inaccurate } \\
\text { understanding of harms } \\
\text { and benefits, and they } \\
\text { described performing } \\
\text { testing to help patients } \\
\text { understand their risk }\end{array}$ \\
\hline $\begin{array}{l}\text { Solomon } \\
\text { et } a \text { P }^{7}\end{array}$ & - & $\begin{array}{l}\text { there was a perception } \\
\text { that real patients differ } \\
\text { from those recruited to } \\
\text { the trials that inform } \\
\text { guidelines }\end{array}$ & $\begin{array}{l}\text { Many GPs felt they } \\
\text { needed } \\
\text { to be able to interpret } \\
\text { guidelines in the context of } \\
\text { individual patients }\end{array}$ & $\begin{array}{l}\text { to reach a compromise } \\
\text { by following guidelines } \\
\text { and accommodating } \\
\text { patient factors, such as } \\
\text { patient preferences or } \\
\text { the patient's ability to } \\
\text { tolerate medicines }\end{array}$ \\
\hline $\begin{array}{l}\text { Anthierens } \\
\text { et } a \text { P }^{8}\end{array}$ & $\begin{array}{l}\text { The coordination of the } \\
\text { medication regime of } \\
\text { different disciplines is a } \\
\text { tough job... }\end{array}$ & $\begin{array}{l}\text { preventive aims are often } \\
\text { minimal considering their } \\
\text { age and polypathology, } \\
\text { which is in contrast with }\end{array}$ & $\begin{array}{l}\text { As a GP you have a } \\
\text { broader view of your } \\
\text { patient. You look at him/ } \\
\text { her from his own life }\end{array}$ & $\begin{array}{l}\text { They have a holistic } \\
\text { view of the patient } \\
\text { because of the } \\
\text { long-standing doctor- }\end{array}$ \\
\hline
\end{tabular}


Table 2 Continued

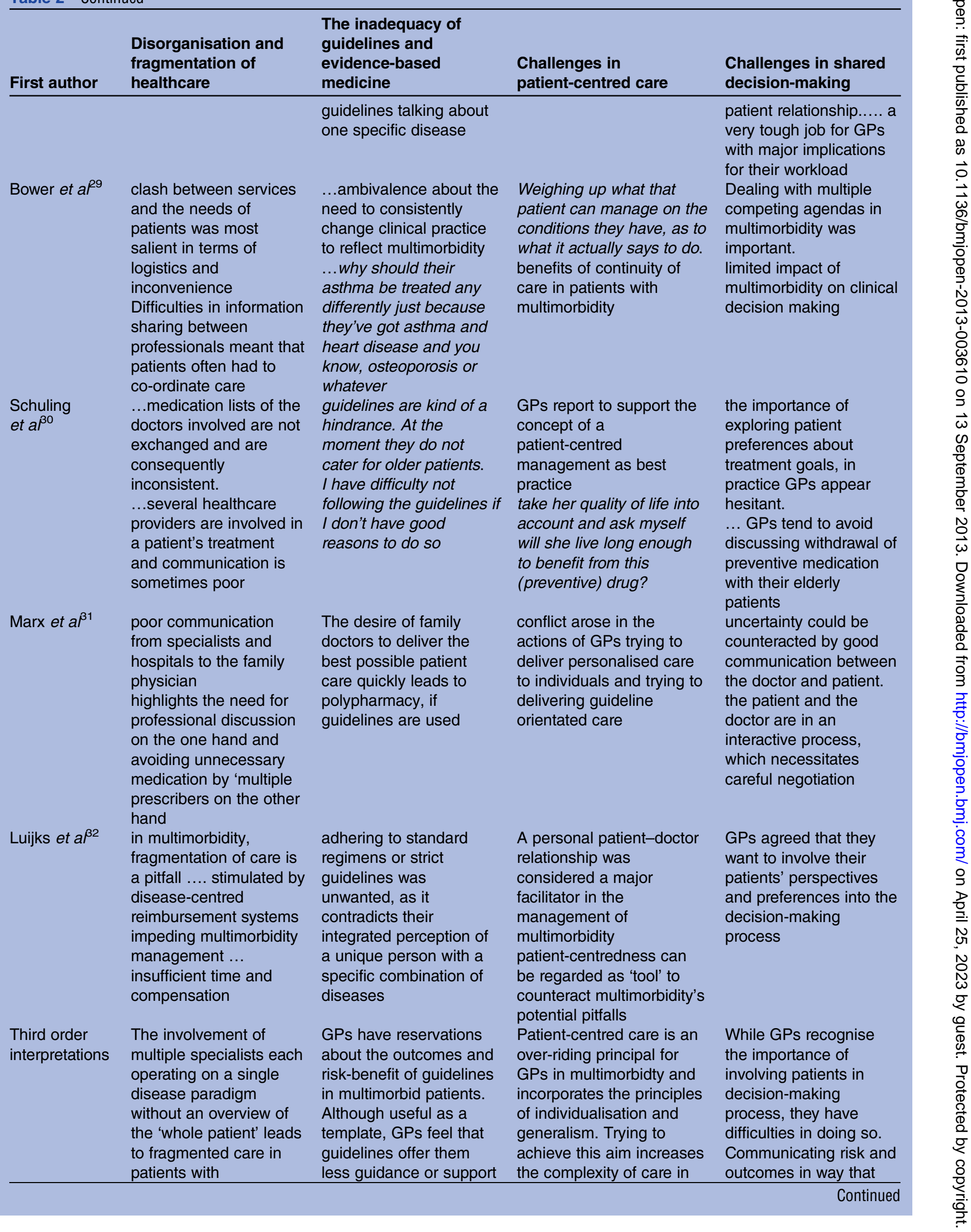


Table 2 Continued

\begin{tabular}{|c|c|c|c|c|}
\hline First author & $\begin{array}{l}\text { Disorganisation and } \\
\text { fragmentation of } \\
\text { healthcare }\end{array}$ & $\begin{array}{l}\text { The inadequacy of } \\
\text { guidelines and } \\
\text { evidence-based } \\
\text { medicine }\end{array}$ & $\begin{array}{l}\text { Challenges in } \\
\text { patient-centred care }\end{array}$ & $\begin{array}{l}\text { Challenges in shared } \\
\text { decision-making }\end{array}$ \\
\hline & $\begin{array}{l}\text { multimorbidity. Single } \\
\text { disease care is } \\
\text { antagonistic to the goals } \\
\text { of GPs in primary care. } \\
\text { This problem is } \\
\text { compounded by poor } \\
\text { co-ordination and } \\
\text { communication within } \\
\text { the health service, } \\
\text { leaving GPs feeling } \\
\text { excluded from their } \\
\text { patients care and with a } \\
\text { sense of uncertainty } \\
\text { regarding their role }\end{array}$ & $\begin{array}{l}\text { for multimorbid patients } \\
\text { and may in fact cause } \\
\text { additional problems } \\
\text { when they try to adhere } \\
\text { to them }\end{array}$ & $\begin{array}{l}\text { some cases, and can lead } \\
\text { the GP into additional } \\
\text { conflict with specialist } \\
\text { services or evidence } \\
\text { based medicine }\end{array}$ & $\begin{array}{l}\text { will engage patients in } \\
\text { the decision-making } \\
\text { process is an area that } \\
\text { GPs feel unskilled in, } \\
\text { thereby limiting the } \\
\text { patients influence as } \\
\text { factor that would help } \\
\text { the decision making } \\
\text { process }\end{array}$ \\
\hline
\end{tabular}

multiple medications. ${ }^{23} 2932$ This burden was compounded by certain patient characteristics such as cognitive or memory problems, poor social supports and finances and low levels of motivation 23-26 $28 \quad 29$ which were likely to affect the patient's ability to understand and adhere to treatment. $252630-32$

\section{Challenges in shared decision-making}

Shared decision-making was considered to be more complicated in the context of multimorbidity due to many of the issues discussed above. The importance of eliciting patient's preferences was widely acknowledged, but GPs had difficulties doing this in practice. ${ }^{30} 32$ GPs reported that many patients actively participate in decision-making, can prioritise and are 'good with trial and error'. ${ }^{29}$ 30 However, for certain patients making choices could be a 'source of distress' and contributed to them becoming 'over the top anxious about their conditions'. ${ }^{29}$ Discussing the risks and outcomes associated with treatment options in a way facilitated that patient involvement was particularly challenging, as was discussing the balance between quantity and quality of life. ${ }^{24-26} \quad 30 \quad 32$ In response to difficulties in shared decision-making, GPs employed a range of techniques including prioritisation of the doctor's or the patient's agenda, $^{28} 29$ avoidance of decision-making, ${ }^{23} 30$ drawing on one's own personal experience ${ }^{31}$ or using additional investigations to support a decision. ${ }^{26}$

Enhanced-communication skills were seen as necessary in multimorbidity to facilitate clear and concise discussion with patients on the interplay between their chronic diseases and to help with de-prescribing medications, which if carried out badly could be interpreted as withdrawing care. ${ }^{26} 3031$ GPs felt that they had a pivotal role to play when patients were in the advanced stages of a chronic disease but due to multimorbidity may no longer be receiving specialist input. In this setting, adopting a palliative approach may be useful when making decisions on medications. ${ }^{30} 32$

\section{Third-order interpretations and the 'line of argument'}

By synthesising the individual contributions of each study to the key concepts, third-order interpretations were generated and linked using a 'line of argument' (table 2).

1. Disorganisation and fragmentation of healthcare: The involvement of multiple specialists and the emphasis on single disease care is antagonistic to the 'holistic' goals of GPs. This problem is compounded by poor co-ordination and communication within the health service, leaving GPs feeling excluded from their patients' care and with a sense of uncertainty regarding their role.

2. The inadequacy of guidelines and evidence-based medicine: Guidelines offer GPs less support in the management of multimorbid patients and may in fact cause additional problems when they try to adhere to them.

3. Challenges in delivering patient-centred care: Patient centredness is an over-riding principal for GPs in multimorbidity but trying to achieve this increases the complexity of care in some cases, and can lead the GP into additional conflict with specialist services or evidence-based medicine.

4. Challenges in shared decision-making: The patient's role in decision-making in multimorbidity is limited by difficulties in communicating risk benefit and outcomes in a field where there is much more uncertainty on these issues. 
These key concepts represent four problematic domains in the provision of healthcare in multimorbidity, as seen by GPs. The line of argument linking these domains suggests that GPs feel isolated in the management of patients with multimorbidity, a group that they are specifically tasked with caring for.

\section{Discussion}

The studies presented here used a bottom-up approach to explore the management of patients with multimorbidity. This article is the first to our knowledge to systemically review and synthesise their findings, and demonstrates the diversity in how GPs see this issue. The difficulties that GPs encounter span a number of clinical domains including system factors, the evidence base for chronic disease management and their own communication skills in the context of multiple physician and patient agendas. These findings are important because they highlight the separate but interacting areas of clinical practice that require intervention to improve care in multimorbidity. Thus, this study is additive to the findings of the individual studies reviewed; synthesising the contributions of existing qualitative investigations in this area has led to a broader description and fuller understanding of the range of challenges that exist. Given the considerable overlap and repetition of data that emerged from the primary studies, it is unlikely that further scoping work on the challenges in multimorbidity will be useful. However, despite the commonalities, the significance of each domain varied between settings. Further research should focus on the reasons why some domains matter more in particular settings and how local factors modify and influence these domains, with a view to exploring the solutions that exist and identifying those solutions. ${ }^{33}$ There will not be a 'one size fits all' intervention to support and improve the quality of care in multimorbidity. However, the domains that have emerged from this review give a useful framework for future work in this field.

\section{Comparison with other research}

\section{Disorganisation and fragmentation of care}

Integrating patient care across services is important in all aspects of medicine, but there is a pressing need to address this in multimorbidity. Patients attending four or more doctors experience problems such as conflicting medical advice, unavailable test results and duplication of tests more commonly. ${ }^{34}$ Our study indicates that, across settings, GPs receive poor communication from other care providers in multimorbidity, leaving them guessing about the course of management. Enhanced use of information technology may support more seamless multimorbidity care, by allowing bidirectional communication and local integration between care providers.

Satisfaction with prevailing health systems also varied between studies. Generalisations relating to a health system cannot be made from one single study, but this divergence is worthy of further exploration. For instance, a comparative analysis, using a multimorbidity perspective, of the strengths and weaknesses between the UK system (which uses explicit quality frameworks for chronic disease management) and a health system without such an approach may help inform policy and the development of interventions at health system level.

\section{Inadequacy of guidelines and evidence-based medicine}

GPs in the studies reviewed here desired evidence on which to base their management but had mixed feelings on the clinical utility of guidelines as they currently stand. This finding is supported by prior studies showing that, internationally, few guidelines offer modified advice for patients with multimorbidity. ${ }^{35} 36$ To increase the relevance of clinical guidelines for multimorbid patient, our findings thus support the call for greater representation of multimorbid patients in trials and greater involvement of GPs in the writing of guidelines. $^{37}$

Chronic diseases can occur in combinations that are concordant (have synergies in treatment) or discordant (conflicting treatments or interactions). ${ }^{4}$ Although the synergies between certain conditions were discussed in the articles reviewed here, examples of specific discordant conditions were rare. It would be useful to explore what discordant combinations commonly occur in practice. This information could be used to inform the development of caveats in guidelines, educational initiatives or prioritisation tools that would support safe approaches to competing diseases. ${ }^{38}$

\section{Delivering patient-centred care}

This domain emerged as an intuitive and over-riding goal of GPs in all studies, and interventions in multimorbidity must help GPs deliver on this aspiration. Continuity of care emerged as an important tenet of patient-centredness and should be promoted in any such interventions. Three subtypes of continuity of care have been previously described ${ }^{39}$; of these, both informational and management continuity were seen here as necessary for patient safety and cohesive management. However, it was relational continuity that appeared to most facilitate care in multimorbidity, by allowing GPs to foster trust, anticipate preferences and empower their patients over time. Multimorbid patients that GPs felt required particular assistance are those with cognitive impairment, mental health issues or low social support, and accordingly may require nuanced interventions to support their care.

\section{Challenges in shared decision-making}

Shared decision-making is facilitated by many aspects of primary care. ${ }^{40-42}$ Nevertheless, GPs in the studies presented here sought additional skills in shared decision-making in multimorbid patients, especially for complex decisions that involve not prescribing or discontinuing medications. It is known that interventions to improve shared decision-making may fail due to barriers such as lack of time and perceived lack of suitability of the patient. ${ }^{43}{ }^{44}$ Given the overlap between these 
barriers and those that GPs encounter in multimorbidity, it is likely that special attention is warranted for the development of models of decision-making for multimorbid patients. Evaluating existing models of shared decision-making, such as the choice talk/option talk/ decision talk model described by Elwyn $e t a t^{45}$, in clinical encounters with multimorbid patients may be a useful place to start this process.

\section{Usefulness of metaethnography}

The systematic approach of metaethnography as applied in this study has several strengths. It provides a fuller description of multimorbidity care while preserving the important contextual features that are inherent in general practice research. Our themes, developed from the experiences of 275 participants, indicated considerable overlap from each of the primary studies. Nevertheless, different opinions within particular themes gave useful insights into how system factors and context can influence practice.

\section{Robustness of findings}

The step-by-step approach followed in our analysis generated themes in a transparent and reproducible manner. The robustness of our findings is supported by several features. First, the quality of the studies reviewed was assessed using a published framework and quality levels were uniformly high. Second, there was concordance in the themes derived by non-clinical and the clinical reviewers on the research team. Third, the findings from our analysis were disseminated to the authors of the primary studies. In the resulting feedback, the authors felt that their results were represented within the findings of the synthesis.

\section{Limitations and challenges}

Retrieving qualitative studies from biomedical databases is challenging despite recent advances in the indexing of qualitative literature. We used validated combinations of qualitative search terms to optimise the list of citations returned. ${ }^{14-17}$ Furthermore, we also used nonbiomedical databases to ensure that relevant articles in the sociology or psychology literature were not missed. ${ }^{18}$

Multimorbidity is not a Medical Subject Heading (MeSH) term and there is a lack of consensus on what the term means or encompasses with regard to diseases and disease severity. ${ }^{46}$ We used a broad but less specific search strategy to account for this (see online supplementary appendix 1), which resulted in the retrieval of articles with important information on multimorbidity, but whose original focus was not on this issue. Achieving consensus on the definition of multimorbidity will be important for the generalisability of findings and evaluation of future interventions in this field.

The term 'multimorbidity' was first discussed in the literature in 1976; however, the first article that we found to have investigated this issue with GPs using qualitative methods was published in 2009. This lag mirrors the recent surge in quantitative research investigating multimorbidity, which may be explained by the increasing prevalence and economic impact of multimorbid patients. ${ }^{47}$

There was no language restriction used for inclusion of studies, and translations of potentially relevant titles and articles were conducted. However, we could have missed articles not listed on English language databases.

Although the quality of included studies was generally good, the over-representation of academic GPs as participants was a potential source of bias and may limit the generalisability of our findings to the overall GP population. Future studies should endeavour to include GPs outside of the academic field to ensure that the full range of clinical challenges is explored.

The primary data in our review originated from focus groups or clinical vignettes, reflecting what clinicians say rather than what they do. It would be valuable to use case-based data in future studies, to see, for example, what specific conflicts arise between guidelines and how shared decision-making is currently broached in practice. Such data would also help inform educational programmes in multimorbidity for GPs and GP trainees.

Our findings are limited to the challenges experienced by healthcare professionals in management of multimorbidity; the patient perspective also requires consideration. Elderly patients report functional decline, poor quality of life and high healthcare costs as major consequences of multimorbidity and accordingly these factors should be incorporated into interventions design in this area. ${ }^{48}$

\section{Conclusions}

This systematic review shows that the problem areas for GPs in the management of multimorbidity may be classified into four domains: disorganisation and fragmentation of healthcare; the inadequacy of guidelines and evidencebased medicine; challenges in delivering patient-centred care and barriers to shared decision-making. There will be no 'one fits all' intervention for multimorbidity but these domains may be useful targets to guide the development of interventions that will assist and improve the provision of care to multimorbid patients.

Contributors CS designed the study, undertook the systematic review, carried out the data extraction, analysis and interpretation and wrote the manuscript. SMH provided guidance on qualitative research methods, participated in the analysis and interpretation of results and reviewed the manuscript. JB participated in the design of the systematic review and critical review of the manuscript. CB participated in the design of the review, analysis and interpretation of results and critical review of the manuscript. CS is the guarantor.

Funding Health Research Board, Ireland, grant numbers HRB*NSAFP/2011/3 (CS) and HRB*ICE/2012/12 (SMH).

Competing interests CS is on an academic fellowship programme sponsored by the Health Research Board and the Health Service Executive, Ireland. SMH is a postdoctoral research fellow funded by the Health Research Board Interdisciplinary Capacity Enhancement Awards.

Provenance and peer review Not commissioned; externally peer reviewed.

Data sharing statement Additional data on the assessment of quality of included papers are available from csinnott@ucc.ie. 
Open Access This is an Open Access article distributed in accordance with the Creative Commons Attribution Non Commercial (CC BY-NC 3.0) license which permits others to distribute, remix, adapt, build upon this work noncommercially, and license their derivative works on different terms, provided the original work is properly cited and the use is non-commercial. See: http:// creativecommons.org/licenses/by-nc/3.0/

\section{REFERENCES}

1. Fortin M, Hudon $\mathrm{C}$, Haggerty J, et al. Prevalence estimates of multimorbidity: a comparative study of two sources. BMC Health Serv Res 2010;10:111

2. van den Akker M, Buntinx F, Metsemakers JF, et al. Multimorbidity in general practice: prevalence, incidence, and determinants of co-occurring chronic and recurrent diseases. J Clin Epidemiol 1998;51:367-75.

3. Bartels CM, Kind AJ, Everett C, et al. Low frequency of primary lipid screening among medicare patients with rheumatoid arthritis. Arthritis Rheum 2011:63:1221-30.

4. Lagu T, Weiner MG, Hollenbeak CS, et al. The impact of concordant and discordant conditions on the quality of care for hyperlipidemia. $J$ Gen Intern Med 2008;23:1208-13.

5. Wolff JL, Starfield B, Anderson G. Prevalence, expenditures, and complications of multiple chronic conditions in the elderly. Arch Intern Med 2002;162:2269-76.

6. Glynn LG, Valderas JM, Healy P, et al. The prevalence of multimorbidity in primary care and its effect on health care utilization and cost. Fam Pract 2011;28:516-23.

7. Fortin M, Soubhi H, Hudon $\mathrm{C}$, et al. Multimorbidity's many challenges. BMJ 2007;334:1016-17.

8. Smith SM, Soubhi H, Fortin M, et al. Managing patients with multimorbidity: systematic review of interventions in primary care and community settings. BMJ 2012;345:e5205

9. Salisbury C. Multimorbidity: time for action rather than words. Br J Gen Pract 2013;63:64-5.

10. Craig P, Dieppe P, Macintyre S, et al. Developing and evaluating complex interventions: the new Medical Research Council guidance. BMJ 2008;337:a1655.

11. Ring N, Jepson R, Ritchie K. Methods of synthesizing qualitative research studies for health technology assessment. Int Jo Technol Assess Health Care 2011;27:384-90.

12. Campbell R, Pound P, Morgan M, et al. Evaluating meta-ethnography: systematic analysis and synthesis of qualitative research. Health Technol Assess 2011;15:1-164.

13. Noblit G, Hare R. Meta-ethnography: synthesizing qualitative studies. Newbury Park, CA: Sage, 1988

14. Wong SS, Wilczynski NL, Haynes RB, et al. Developing optimal search strategies for detecting clinically relevant qualitative studies in MEDLINE. Studies Health Technol Inform 2004;107:311-16.

15. Wilczynski NL, Marks S, Haynes RB. Search strategies for identifying qualitative studies in CINAHL. Qual Health Res 2007:17:705-10.

16. Walters LA, Wilczynski NL, Haynes RB, et al. Developing optimal search strategies for retrieving clinically relevant qualitative studies in EMBASE. Qual Health Res 2006;16:162-8.

17. McKibbon KA, Wilczynski NL, Haynes RB. Developing optimal search strategies for retrieving qualitative studies in PsycINFO. Eval Health Prof 2006;29:440-54.

18. Atkins $\mathrm{S}$, Lewin $\mathrm{S}, \mathrm{Smith} \mathrm{H}$, et al. Conducting a meta-ethnography of qualitative literature: lessons learnt. BMC Med Res Methodol 2008;8:21.

19. CASP Qualitative Appraisal Checklist. Critical Appraisal Skills Programme [Internet]. 2006.

20. Joanna Briggs Institute Reviewers' Manual: 2008 edition: The Joanna Briggs Institute.

21. QSRInternational. NVivo qualitative data analysis software. 9th edn. 2010.

22. Tong A, Flemming $\mathrm{K}$, Mclnnes $\mathrm{E}$, et al. Enhancing transparency in reporting the synthesis of qualitative research: ENTREQ. BMC Med Res Methodol 2012:12:181.

23. Smith SM, O'Kelly S, O'Dowd T. GPs' and pharmacists' experiences of managing multimorbidity: a 'Pandora's box'. Br J Gen Pract 2010;60:285-94.
24. O'Brien R, Wyke S, Guthrie B, et al. An 'endless struggle': a qualitative study of general practitioners' and practice nurses' experiences of managing multimorbidity in socio-economically deprived areas of Scotland. Chronic IIIn 2011;7:45-59.

25. Steinman MA, Sudore RL, Peterson CA, et al. Influence of patient age and comorbid burden on clinician attitudes toward heart failure guidelines. Am J Geriatr Pharmacother 2012;10:211-18.

26. Fried TR, Tinetti ME, lannone L. Primary care clinicians' experiences with treatment decision making for older persons with multiple conditions. Arch Intern Med 2011;171:75-80.

27. Solomon J, Raynor DK, Knapp P, et al. The compatibility of prescribing guidelines and the doctor-patient partnership: a primary care mixed-methods study. Br J Gen Pract 2012;62:e275-81.

28. Anthierens S, Tansens A, Petrovic M, et al. Qualitative insights into general practitioners views on polypharmacy. BMC Fam Pract 2010;11:65.

29. Bower P, Macdonald W, Harkness E, et al. Multimorbidity, service organization and clinical decision making in primary care: a qualitative study. Fam Pract 2011;28:579-87.

30. Schuling J, Gebben H, Veehof LJ, et al. Deprescribing medication in very elderly patients with multimorbidity: the view of Dutch GPs. A qualitative study. BMC Fam Pract 2012;13:56.

31. Marx G, Pusche K, Ahrens D. Polypharmacy: a dilemma in primary care? Results of group discussions with general practitioners. Gesundheitswesen 2009;71:339-48.

32. Luijks HD, Loeffen MJW, Lagro-Janssen AL, et al. GPs considerations in multimorbidity management: a qualitative study. $\mathrm{Br}$ $J$ Gen Pract 2012:62:503-10.

33. Lemmens KM, Nieboer AP, Rutten-Van Molken MP, et al. Bottom-up implementation of disease-management programmes: results of a multisite comparison. BMJ Qual Saf 2011;20:76-86.

34. Schoen C, Osborn R, Squires D, et al. New 2011 survey of patients with complex care needs in eleven countries finds that care is often poorly coordinated. Health Aff 2011;30:2437-48.

35. Fortin M, Contant E, Savard C, et al. Canadian guidelines for clinica practice: an analysis of their quality and relevance to the care of adults with comorbidity. BMC Fam Pract 2011;12:74.

36. Boyd CM, Darer J, Boult C, et al. Clinical practice guidelines and quality of care for older patients with multiple comorbid diseases. JAMA 2005;294:716-24.

37. Starfield B. Threads and yarns: weaving the tapestry of comorbidity. Ann Fam Med 2006;4:101-3.

38. Guthrie B, Payne K, Alderson P, et al. Adapting clinical guidelines to take account of multimorbidity. BMJ 2012;345:e6341.

39. Haggerty JL, Reid RJ, Freeman GK, et al. Continuity of care: a multidisciplinary review. BMJ 2003;327:1219-21.

40. Charles C, Gafni A, Whelan T. Shared decision-making in the medical encounter: what does it mean? (or it takes at least two to tango). Soc Sci Med 1997;44:681-92.

41. Murray E, Charles C, Gafni A. Shared decision-making in primary care: tailoring the Charles model to fit the context of general practice. Patient Educ Couns 2006;62:205-11.

42. Kadam U. Redesigning the general practice consultation to improve care for patients with multimorbidity. BMJ 2012;345:e6202.

43. Legare F, Ratte S, Stacey D, et al. Interventions for improving the adoption of shared decision making by healthcare professionals. Cochrane Database Syst Rev 2010;5:CD006732.

44. Legare F, Ratte S, Gravel K, et al. Barriers and facilitators to implementing shared decision-making in clinical practice: update of a systematic review of health professionals' perceptions. Patient Educ Couns 2008;73:526-35

45. Elwyn G, Frosch D, Thomson R, et al. Shared decision making: a model for clinical practice. J Gen Intern Med 2012;27:1361-7.

46. Huntley AL, Johnson R, Purdy S, et al. Measures of multimorbidity and morbidity burden for use in primary care and community settings: a systematic review and guide. Ann Fam Med 2012;10:134-41.

47. Barnett K, Mercer SW, Norbury M, et al. Epidemiology of multimorbidity and implications for health care, research, and medical education: a cross-sectional study. Lancet 2012;380:37-43.

48. Marengoni A, Angleman S, Melis R, et al. Aging with multimorbidity: a systematic review of the literature. Ageing Res Rev 2011;10:430-9. 